\title{
PARTICIPATIVE DECISION MAKING AND EMPLOYEE PERFORMANCE IN DIFFERENT CULTURES: THE MODERATING EFFECTS OF ALLOCENTRISM/IDIOCENTRISM AND EFFICACY
}

\author{
SIMON S. K. LAM \\ University of Hong Kong \\ XIAO-PING CHEN \\ University of Washington \\ JOHN SCHAUBROECK \\ Drexel University
}

\begin{abstract}
The relationship between perceived participative decision making and employee performance was examined in matched samples of employees from the Hong Kong and U.S. branches of one organization. Self-efficacy in regard to participating in decisions and idiocentrism moderated the relationship between perceived participative decision-making opportunity and individual performance. Perceptions of the participation efficacy of a work unit and allocentrism moderated the relationship between participative decision-making opportunity and group performance. Idiocentrism and allocentrism appeared to explain regional differences in how participative decision making and efficacy perceptions interacted to predict performance.
\end{abstract}

Participative decision making, defined as joint decision making (Locke \& Schweiger, 1979) or influence sharing between hierarchical superiors and their subordinates (Mitchell, 1973), has been a focus of organizational research for nearly 50 years. Whereas many researchers have examined relationships between participative decision making and employee outcomes such as task performance, job satisfaction, and turnover, only equivocal conclusions can be drawn from existing research on the relationship between participative decision making and job performance. Some quantitative reviews have reported moderately positive relationships between these variables (e.g., Cotton, Vollrath, Froggatt, Lengnick-Hall, \& Jennings, 1988; Miller \& Monge, 1986). Other quantitative reviews have not found these positive effects (e.g., Wagner, 1994; Wagner \& Gooding, 1987a, 1987b). Wagner and Gooding (1987a) inspected the studies cited by Miller and Monge (1986) and found that 90 percent involved percept-percept data collection techniques (that is, data collected from the same respondents using the same questionnaire at the same time). Wagner (1994) reanalyzed Cotton and his coauthors' (1988) data using meta-analysis and

The authors thank Thomas Lee, Terence Mitchell, and Marilyn Gist for their constructive and thoughtful comments on a draft. Part of the results of this study was presented at the Asia Academy of Management Meeting in Singapore, 2000. found that the overall effect of employee participative decision making on job performance (and job satisfaction) was positive but small, especially when the unisource studies were omitted. Wagner and his colleagues (1994; Wagner \& Gooding, $1987 \mathrm{a}, 1987 \mathrm{~b}$ ) thus argued that the significant performance-related findings published in participative decision making research were mainly the product of percept-percept artifacts. Although these inferences about the main effects of participative decision making appear sound, the inconsistent findings concerning the participation-performance relationship might also be explained by the absence (or presence) of other moderating variables. Indeed, Wagner and Gooding (1987b) noted that the moderating effects of other variables could hide a few noteworthy multisource relationships. The moderating effects of situational variables (work group size, task complexity, and others) have been well documented (Wagner \& Gooding, 1987b). Therefore, the present study focused on testing the moderating effects of societal culture and psychological variables on group and individual performance. In particular, we focus here on individual difference variables associated with locus of identity and efficacy beliefs about participating as moderators of the effects of participative decision making on individual and group performance. Below, we discuss how these factors interact with participative decision making in influencing individual and group performance. 


\section{THEORETICAL BACKGROUND}

\section{Allocentrism, Collective Efficacy, and Group Performance}

In the present study, we distinguished between two types of beliefs a person may have about his or her efficacy in participating in work decisions: participation efficacy (self) and participation efficacy (collective). Drawing on previous definitions of self-efficacy (Bandura, 1997) and collective efficacy (Gist, 1987; Earley, 1994; Mischel \& Northcraft, 1997; Riggs, Warka, Babasa, Betancourt, \& Hooker, 1994), we define participation efficacy (self) as the extent to which an individual believes that he or she has the ability and skills to successfully participate in decision-making processes. Participation efficacy (collective) is the extent to which group members believe that their group has the ability and skills to successfully participate in decision making. In theory, participative decision making's effects on performance may stem from how people use it instrumentally to create situations that are more favorable to their effectiveness (Mitchell, 1973). People who are high on self-efficacy will utilize participative decision making opportunities to achieve what they desire, whereas those who are low on self-efficacy may tend to become distressed when presented with such opportunities. Similarly, people who have high levels of collective efficacy are likely to participate actively when they have the opportunity because they are confident that, together with their peers, they can effectively increase group performance. On the other hand, persons who have low levels of collective efficacy may tend to view such opportunities as threatening because they view their group as being unable to make decisions effectively. An opportunity for their group to participate in decision making may be seen as surfacing group dysfunctions toward no clear benefit. Thus, the degree to which employees believe that they or their work units are able to participate effectively (have participation efficacy) is critical in determining how strongly participative decision making influences performance.

Whereas individualism and collectivism represent the general attributes of a given culture, the terms "idiocentrism" and "allocentrism" have been used to measure the individual-level orientations that reflect these cultural values (Triandis, 1989). Triandis suggested using idiocentrism and allocentrism to capture within-culture variation in personality attributes. Idiocentrics view the self as being separate from others, are concerned with achievement, and give priority to personal goals over the goals of collectives. Conversely, persons scoring high on allocentrism view the self as inseparable from the others in an in-group. They are so concerned with interpersonal harmony that, when they do distinguish between personal and collective goals, they subordinate their personal goals to the collective goals. From the individual perspective, according to Triandis, idiocentrism and allocentrism are distinct constructs measurable along a normal distribution. Common societal influences tend to make one of these two dimensions higher on the average in any particular societal culture; however, individuals often differ from their society's trends.

The developing literatures on shared mental models (e.g., Mathieu, Heffner, Goodwin, Salas, \& Cannon-Bowers, 2000) and "transactive memory" in groups (e.g., Liang, Moreland, \& Argote, 1995) suggest that group members develop shared images of their groups. According to both these frameworks, shared experiences lead group members to develop interrelated knowledge structures that facilitate (or hinder) group process. For example, Cannon and Edmondson (2001) found that group performance was associated with members' shared beliefs about how to learn from failure. The identities of allocentric individuals tend to be grounded in goals that they share with other members of their groups (Chen, Chen, \& Meindl, 1998). When these people have little confidence in a group's ability to effectively confront challenges, they may see influence opportunities as debilitating rather than salutary for performance because they could create new conditions for group failure. Moreover, because allocentric persons' perceptions of collective efficacy have primacy over their perceptions of self-efficacy, personal influence opportunities may lead to person-role conflicts if they do not see a group as working together effectively. Thus, groups whose members are predominantly highly allocentric can be expected to respond effectively when they have opportunities to participate in decisions, but only when they share high participation efficacy (collective).

There has been limited cross-cultural research on self-efficacy and collective efficacy (see Earley, 1994; Gibson, 1999; Schaubroeck, Lam, \& Xie, 2000). Schaubroeck and his coauthors (2000) did not examine performance outcomes, but they found that having more job-related discretion (job control) enhanced stress-coping facility among allocentric persons only when they also reported high collective efficacy. Job control and participative decision making opportunity are similar in that both reflect an employee's level of influence at work, and both job performance and stress coping reflect how effectively a person is using influence opportunities. Thus, their study suggests that, at least at the individual level, "allocentrics"” confidence in their work 
groups may determine how effectively they use influence opportunities in group contexts.

In view of the existing research and theory, we predict that, among work unit members with high allocentrism, collective efficacy cognitions concerning the use of influence will determine how successfully their work units use opportunities to participate in decision making to enhance group performance.

Hypothesis 1a. Perceptions of an opportunity for participative decision making will have a positive effect on the performance of a group when the group (a) is high on allocentrism and (b) has high participation efficacy.

Hypothesis $1 b$. Perceptions of an opportunity for participative decision making will have a negative effect on the performance of a group when the group is (a) high on allocentrism and (b) has low participation efficacy.

\section{Idiocentrism, Self-Efficacy, and Individual Performance}

Idiocentric persons are less motivated to cooperate with other group members outside the context of their individual roles, and thus, collective efficacy cognitions have little primacy. Because they value individual achievement and autonomy, however, "idiocentrics" can be expected to use influence opportunities as a means of pursuing the rewards associated with effective individual performance. In the study by Schaubroeck and his colleagues cited above (Schaubroeck et al., 2000), among more idiocentric persons with high job control, collective efficacy did not enhance coping as it did among allocentrics; rather, self-efficacy on the job played the crucial moderating role. Similarly, whether idiocentric workers use influence opportunities effectively or ineffectively to achieve their personal performance goals may depend on their domain-specific self-efficacy. Specifically, when idiocentric workers lack confidence in their own ability to participate in decision making, they may be less inclined to involve themselves in decisions when opportunities to participate arise. They may hold back because having more influence opportunities creates conditions in which they expect to fail. Moreover, persons scoring high on idiocentrism place high credence in individual differences in merit in various domains. Therefore, those who lack confidence in their participative decisionmaking abilities may fear embarrassment or ridicule if they offer their views and opinions. In addition, unlike people high on allocentrism, idiocentrics may be less inclined to view participative decision making as a group responsibility in which their own identity and limitations are submerged in a collective effort. For these reasons, the individual performance of idiocentrics who have low participation efficacy (self) is not likely to benefit from participative decision making opportunities. On the other hand, because of their emphasis on personal achievement, idiocentric people who have high participation efficacy (self) may readily seek to obtain the individual performance rewards that participating can facilitate through such mechanisms as helping individuals clarify and negotiate role expectations, enhancing their performance expectancies, and removing performance barriers (Mitchell, 1973; Schuler, 1980).

Hypothesis 2a. Perceptions of an opportunity for participative decision making will have a positive effect on the performance of an individual when the individual is high on (a) idiocentrism and (b) participation efficacy (self).

Hypothesis 2b. Perceptions of an opportunity for participative decision making will have a negative effect on the performance of an individual when the individual ( $a$ ) is high on idiocentrism and (b) has low participation efficacy (self).

\section{METHODS}

\section{Sample and Procedures}

An important methodological issue in conducting cross-cultural research is the comparability of different samples on dimensions that are not central to the investigation (Brislin, Lonner, \& Thorndike, 1973). In the present study, our samples were matched in terms of organization, job, and numerous demographic characteristics. The respondents were junior workers in the Hong Kong and U.S. branches of a large multinational bank. All the branches were divided into either four- or fivemember units, each of which reported to a single supervisor, who in turn reported to an operating supervisor. These two national samples did not differ significantly in age, gender, education, or tenure. Age ranged from 20 to 38, with the mean age being 25.4 years; 82 percent were women; 94 percent had at least high school educations; and 8 percent had undergraduate degrees. The respondents had been employed in their present positions from 1 to 7 years, with the mean tenure being 2.7 years.

Questionnaires were sent to potential participants through the company's internal mail system. Respondents were guaranteed anonymity and pro- 
vided with stamped envelopes preaddressed to the researchers. We asked respondents to provide their employee numbers so that we could match responses with job performance data. They were assured that these numbers would be used strictly for research purposes and would not be associated with their names. To maintain confidentiality of the responses, we processed the data off-site and reported only aggregated data to the organization.

Questionnaires were sent to 338 junior workers in Hong Kong, and 265 (78\%) returned them. Five workers did not provide their employee identification numbers, and supervisor performance ratings were missing for seven workers. They were excluded from the analysis. Questionnaires were sent to 358 junior workers in the United States, and 288 $(80 \%)$ were returned. We excluded 6 U.S. workers who did not provide their identification numbers and 9 for whom supervisor performance ratings were absent. To determine the representativeness of the sample, we compared data from the respondents with company data measuring (1) the total employee population of junior workers of the organization and (2) the employees who received the mailing in each country. There were no significant differences between the respondents and those who did not respond in terms of age, gender, education, and tenure. Also, the respondents did not differ significantly from the total junior worker population of the organization on any demographic variable in either sample. All Hong Kong participants were of Chinese ethnic origin. The ethnic heritage of the U.S. participants, obtained from archival records, is as follows: 72.8 percent Caucasian-American, 11.5 percent Asian-American, 9.7 percent Hispanic-American, 5.2 percent AfricanAmerican, and 0.8 percent Native American.

\section{Measures}

The questionnaire distributed in Hong Kong was written in Chinese. The conventional method of back-translation (Brislin et al., 1973) was used to translate the measures from English to Chinese. The translators were professionals in this practice with college education in translation. The translated version was pretested with several junior workers in the organization who were asked to comment on any item that they found ambiguous or difficult to understand. These queries did not reveal any major changes that needed to be made to any of the items. ${ }^{1}$

\footnotetext{
${ }^{1}$ We conducted a confirmative factor analysis to ensure the equality of factor structure across the two na-
}

Participative decision making opportunity. Participative decision making opportunity was measured with the five-item scale adopted from Siegel and Ruh (1973). The items essentially ask individuals to indicate the degree of participation they have in decisions affecting their jobs (for example, "In this organization, I have high degree of influence in company decisions," "In this organization, I often participate in decisions regarding my job," "In this organization, I have high degree of influence in the decisions affecting me," "In this organization, I can participate in setting new company policies," and "In this organization, my views have a real influence in company decisions"). The response categories ranged from 1 ("strongly disagree") to 5 ("strongly agree"). The Cronbach alpha for this scale was .95 .

Participation efficacy. The participation efficacy (self) scale was adapted from the Personal Efficacy Beliefs Scale developed by Riggs et al. (1994) and contained five items (for example, "I have confidence in my ability to participate effectively" and "I have excellent participation skills"). Participation efficacy (collective) was adapted from the Collective Efficacy Beliefs Scale (Riggs et al., 1994). The scale consists of five items (for example, "The unit I work with has above-average ability to participate effectively" and "The members of this unit have excellent participation skills"). Both scales were based on a five-point scale ranging from 1 ("very inaccurate") to 5 ("very accurate"). The alphas for these two scales were .90 and .90 , respectively.

Individual and group performance. The immediate unit supervisors were asked to provide a performance rating for each individual employee. We adapted three items from an instrument developed by Heilman, Block, and Lucas (1992): "This employee is very competent," "This employee gets his or her work done very effectively," and "This employee has performed his/her job well." The supervisors returned these ratings directly to us. They also provided performance ratings for each whole unit they supervised, using three items, again adapted from Heilman et al. (1992): "This unit is very competent," "This unit gets the work done very effectively," and "This unit has performed the job well." The alphas for these two scales were .94 and .95 , respectively.

tions, examining each instrument separately using LISREL 8 (Jöreskog \& Sörbom, 1993). The results indicated that a factor structure specifying the unidimensionality of all constructs was consistent with the data for both countries. Details concerning these analyses are available from the first author. 
Allocentrism and idiocentrism. Two separate eight-item scales developed by Triandis and Gelfand (1998) were used to measure allocentrism (for example, "I feel good when I cooperate with others" and "If a co-worker gets a prize, I would feel proud") and idiocentrism (for example, "My personal identity, independent of others, is important to me" and "I would rather depend on myself than others"). The reliabilities for allocentrism and idiocentrism were .92 and .91 , respectively.

\section{Aggregation Tests}

Testing for group-level effects requires opportunity for participative decision making, allocentrism, and participation efficacy (collective) to be aggregated by taking the average of group members' scores. To test the suitability of such aggregation, both between-group differences and within-group agreement on these measures had to be examined (Goodman, Ravlin, \& Schminke, 1990). We estimated within-group agreement $\left(r_{\mathrm{wg}}\right)$ using a method developed by James, Demaree, and Wolf (1993), which assesses the consistency within a group with respect to ratings of a common scale. The average $r_{\mathrm{wg}}$ coefficients for the Hong Kong and U.S. samples respectively were .90 and .87. Every group's coefficient was above .85 , demonstrating within-group agreement. To verify between-groups differences, we conducted a within and between analysis (WABA; Dansereau, Alutto, and Yammarino, 1984). In this test, a statistic, eta, obtained between groups is compared to that obtained within a group in terms of a value called the $E$ ratio, a test of practical significance. The $E$ ratio for the Hong Kong sample was 1.5, and for U.S. sample it was 1.3. That these ratios were greater than 1.0 indicated that the variation between groups was significantly greater than the variation within groups. We computed corrected $F$-tests for each measure, and all results were statistically significant. Together, these results indicate that it is appropriate to infer group-level constructs for each work unit's average individual scores on each variable.

\section{RESULTS}

Table 1 shows the means, standard deviations, and correlations among the variables for the two samples. The Hong Kong means were significantly higher than the U.S. means on individual performance $(t=2.23, p<.05)$, participation efficacy (collective) $(t=4.18, p<.0001)$, and allocentrism $(t=4.36, p<.0001)$, whereas the U.S. means were higher than the Hong Kong means on participation efficacy (self) ( $t=-3.62, p<.001)$ and idiocentrism $(t=-6.32, p<.0001)$.

Hypotheses $1 \mathrm{a}$ and $1 \mathrm{~b}$ predict that allocentrism and participation efficacy (collective) will moderate the relationship between participative decision making opportunity perceptions and group performance. As Table 2 shows, the three-way interaction (participative decision making $\times$ participation efficacy [collective] $\times$ allocentrism) was significant $\left(\Delta R^{2}=.12, F_{1,102}=12.35, p<.001\right)$, providing support for the first set of hypotheses. Specifically, we found that within the group of participants scoring high on allocentrism, strong positive relationships between an opportunity to participate in decisions and group performance were present, but only among participants reporting high participation efficacy (Hypothesis 1a). We also found that within the subgroup with low participation efficacy (collective), participative decision making opportunity was negatively related to group performance (Hypothesis 1b). Moreover, in the groups scoring low on allocentrism, there was no relationship between participative decision making opportunity and group performance. We then used the hierarchical linear cross-level modeling procedure recommended by Hofmann (1997) to test whether the group-level effects still held when individual effects were controlled. Results of these analyses revealed that the group-level effects on group-level performance were significant $(p<.001)$ even after we controlled for both the effects of individuallevel performance and the effects of idiocentrism and individual efficacy $(p<.001)$.

Hypotheses $2 a$ and $2 b$ predict that idiocentrism and participation efficacy (self) will moderate the relationship between participative decision making opportunity perceptions and individual performance. As shown in Table 2, we found that the three-way interaction between participative decision making opportunity, participation efficacy (self), and idiocentrism was significant $\left(\Delta R^{2}=.13\right.$, $F_{1,515}=13.44, p<.001$ ). In particular, for those who scored high on both idiocentrism and participation efficacy (self), there was a strong, positive relationship between participative decision making opportunity and individual performance (Hypothesis 2a). The same relationship was negative among those who reported low participation efficacy and high idiocentrism (Hypothesis 2b). Furthermore, among those who scored low on idiocentrism, regardless of participation efficacy (self) levels, there was no relationship between participative decision making opportunity and performance. These results support the second set of hypotheses.

We performed further analyses to examine (1) whether the U.S. and Hong Kong samples, which 


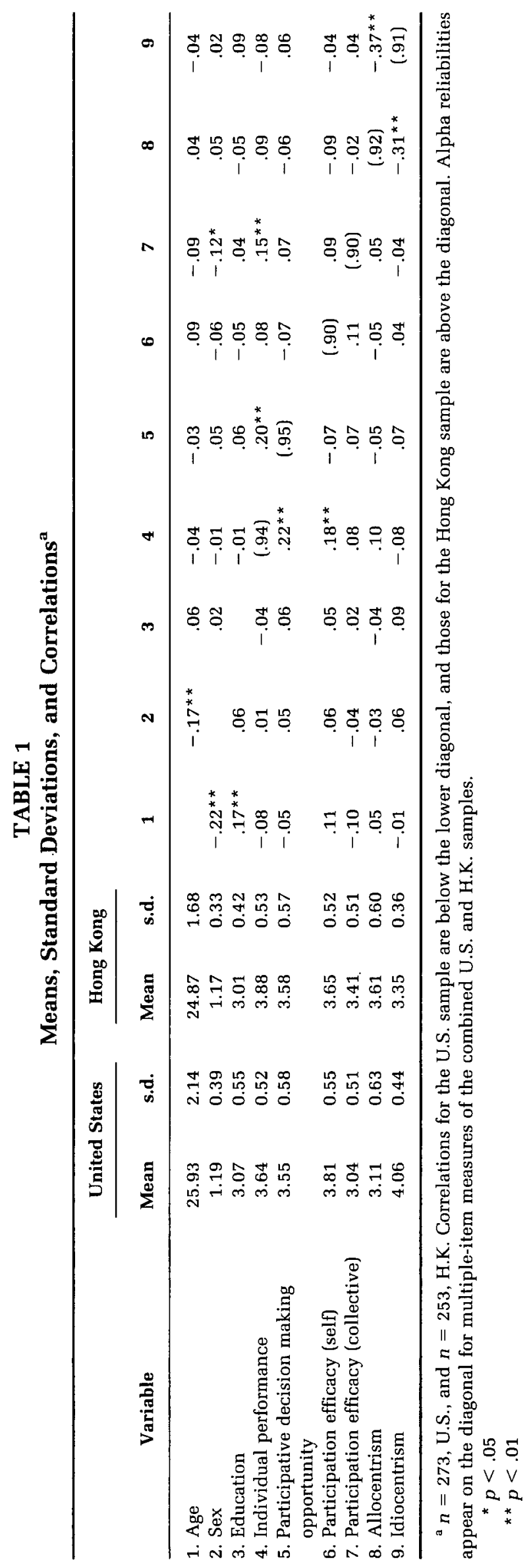


TABLE 2

Results of Regression Analyses ${ }^{a}$

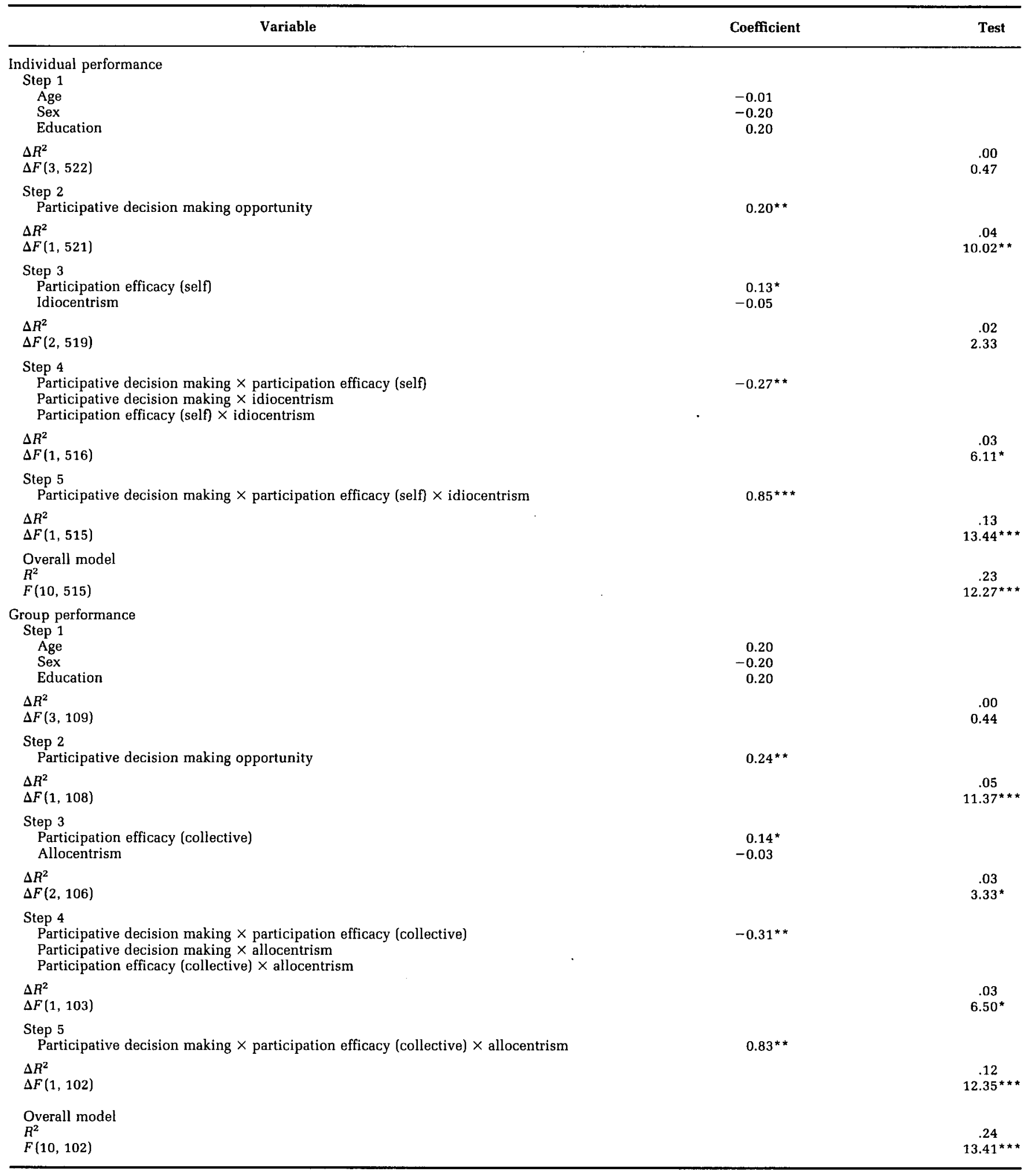

${ }^{a}$ Coefficients are unstandardized. Intercepts are omitted. Participative decision making, participation efficacy (self and collective), idiocentrism, and allocentrism were mean-centered.

$$
\begin{aligned}
{ }^{*} p & <.05 \\
{ }^{\star *} p & <.01 \\
{ }^{* *} p & <.001
\end{aligned}
$$


differed significantly on idiocentrism and allocentrism, also differed significantly regarding the effects of participative decision making opportunity on individual and group performance and (2) whether the effects of idiocentrism and allocentrism mediated the geographic differences. At the group level of analysis, the three-way interaction between participation efficacy (collective), participative decision making opportunity, and U.S.Hong Kong sample were no longer significant predictors of group performance after we controlled for allocentrism and its two-way and three-way interactions with participation efficacy (collective) and participative decision making opportunity $\left(\Delta R^{2}=.00, F_{1,98}=1.37\right.$, n.s. $)$. Similarly, the interaction between participation efficacy (self), participative decision making opportunity, and sample was no longer significant in predicting individual performance after we controlled these variables $\left(\Delta R^{2}=.00, F_{1.511}=1.22\right.$, n.s.). These findings suggest that allocentrism and idiocentrism mediate societal differences in the effects of participative decision making and efficacy beliefs on performance.

\section{DISCUSSION}

The results of the present study suggest that in studying the participation-performance relationship, researchers should look beyond situational and methodological moderators and examine psychological predispositions. We found that individual self-construal (as reflected by allocentrism and idiocentrism) and domain-specific efficacy perceptions significantly determined the magnitude of participative decision making effects. We also observed that allocentrism (aggregated to a workgroup level) and idiocentrism mediated the relationships between the societal difference represented in our two samples (from Hong Kong and the United States) and group and individual performance, respectively. These findings suggest that allocentrism and idiocentrism are powerful individual differences that, although cultivated differently in particular societies, also have meaningful influences on behavior irrespective of societal boundaries. That is to say, even in the United States, where individualism is predominant, allocentric values may influence the effect of participative decision making opportunities on how much employees contribute to their work groups' performance. Similarly, for Hong Kong employees who are more idiocentric, the effect of participative decision making opportunities on individual performance will likely be influenced by their individual self-efficacy. Individual belief structures such as allocentrism aid in identifying aggregate (group, organization, and society) propensities, and they also facilitate understanding why certain norms and stereotypes imputed to a culture often do not represent particular individuals within that culture. Moreover, when organizational or societal cultures are in transition, conceptualizations of beliefs at the individual level and their corresponding measures may better reflect the subtle nature of changes in belief structures.

\section{Limitations}

Given the cross-sectional data used here, our interpretations of causality need to be based on (1) theoretical grounds and (2) complex patterns of interaction and covariation. Previous studies (e.g., Mitchell, 1973) support the notion that having the opportunity to participate in decisions causes higher performance. In addition, it seems unlikely that the complex and yet interpretable interactions we captured represent response set artifacts. On the other hand, longitudinal data may better allow for testing these relationships because levels of participative decision making and efficacy may be somewhat unstable, and their influences on performance may require time to materialize. We believe that common method variance had little influence on the findings because the study had multisource data (supervisory ratings of performance matched with individuals' self-reports). However, future studies could improve on the present one by incorporating some form of participative decision making manipulation (with a corresponding control group) and bracketing changes in individual and group performance over time. Using a single occupation for this study ensured a strong match between the samples across cultures, but it likely led to less variation on some of the variables than would be observed in more occupationally heterogeneous data.

\section{Conclusions}

Compared to the Hong Kong participants, the U.S. participants scored higher on idiocentrism and reported higher participation efficacy (self), whereas the Hong Kong participants scored higher on allocentrism and reported higher participation efficacy (collective) than their U.S. counterparts. Just as societal and local culture teaches people what ideals to hold and what beliefs to endorse, it plays a role in how people construct efficacy expectations (Bandura, 1997). In societies that encourage individualistic values, people pay more attention to themselves, know more about themselves than about others, and are more likely to 
change situations to fit their own desires rather than change themselves to fit situations. Consequently, Americans and other members of individualistic societies may tend to have more confidence in their own abilities, and self-efficacy has more primacy as an influence on behavior in these societies than does collective efficacy. In contrast, the Chinese culture emphasizes collectivist values, so people pay more attention to others and tend to describe themselves in terms that reflect their collective self (for a review, see Triandis [1989, 1994]). As a result, Chinese people tend to have more confidence in their groups' capabilities, and this collective efficacy more readily guides their behavior within group contexts than does self-efficacy. Because judgments of efficacy have a significant influence on employee job performance, especially when the type of efficacy (individual or collective) corresponds to culture-driven personality traits (for example, allocentrism and idiocentrism) and pertinent performance criteria, it is important to include cultural variables in efficacy-performance studies.

As organizations increasingly introduce programs oriented toward participative decision making in order to facilitate reengineering, enrich jobs, and develop high-commitment workplaces, the cultural values and efficacy beliefs held by employees may have unexpected effects. For example, participative goal setting between a supervisor and a subordinate on a one-on-one basis with an emphasis on individual performance may be less successful if the subordinate has strong allocentric beliefs. If it is done on a team basis and the emphasis is on team performance, its effect may not be significant if the subordinates hold individualistic values. Given the concern for and emphasis on diversity in the U.S. workplace, managers must identify individual differences that may influence the desired outcomes of participative decision making and target training programs accordingly, rather than exhort employees to conform to a desired vision of participative decision making or select new employees on the basis of such conformity. Participative decision making interventions will be more successful to the extent that program developers match them to the values of target recipients and train them in ways that increase their most relevant efficacy cognitions (collective efficacy or selfefficacy).

From a research perspective, our findings show that participative decision making can have significant positive or negative effects on employee performance that are not attributable to methodological artifacts. Whereas Wagner (1994), and others have argued that employee participation likely has at best weak effects on individual and group per- formance, the moderators identified in this study suggest conditions under which higher participative decision making effects may be generally observed. To our knowledge none of the studies reviewed in the meta-analyses measured self or collective participation efficacy, and very few if any participative decision making studies have measured individualism and collectivism. Thus, it is plausible that very strong effects, like those we observed in particular subgroups within our study, might also have been present (but not measured) in prior participative decision making studies. Organizations can act to increase or decrease the levels of these moderator variables within their workforces and potentially amplify the positive performance effects of employee participation.

\section{REFERENCES}

Bandura, A. 1997. Self-efficacy: The exercise of control. New York: Freeman.

Brislin, R. W., Lonner, W., \& Thorndike, R. M. 1973. Cross-cultural research methods. New York: Wiley.

Cannon, M. D., \& Edmondson, A. C. 2001. Confronting failure: Antecedents and consequences of shared beliefs about failure in organizational work groups. Journal of Organizational Behavior, 22: 161-177.

Chen, C. C., Chen, X. P., \& Meindl, J. R. 1998. How can cooperation be fostered? The cultural effects of individualism-collectivism. Academy of Management Review, 23: 285-304.

Cotton, J. L., Vollrath, D. A., Froggatt, K. L., LengnickHall, M. L., \& Jennings, K. R. 1988. Employee participation: Diverse forms and different outcomes. Academy of Management Review, 13: 8-22.

Dansereau, F., Alutto, J. A., \& Yammarino, F. J. 1984. Theory testing in organizational behavior: The variant approach. Englewood Cliffs, NJ: PrenticeHall.

Earley, P. C. 1994. Self or group? Cultural effects of training on self-efficacy and performance. Administrative Science Quarterly, 39: 89-117.

Gibson, C. B. 1999. Do they do what they believe they can? Group-efficacy beliefs and group performance across tasks and cultures. Academy of Management Journal, 42: 138-152.

Gist, M. E. 1987. Self-efficacy: Implications for organizational behavior and human resource management. Academy of Management Review, 12: 472-485.

Goodman, P. S., Ravlin, E. C., \& Schminke, M. 1990. Understanding groups in organizations. In L. L. Cummings \& B. M. Staw (Eds.), Leadership, participation, and group behavior: 323-385. Greenwich, CT: JAI Press.

Heilman, M. E., Block, C. J., \& Lucas, J. A. 1992. Pre- 
sumed incompetent? Stigmatization and affirmative action efforts. Journal of Applied Psychology, 77: $536-544$

Hofmann, D. A. 1997. An overview of the logic and rationale of hierarchical linear models. Journal of Management, 23: 723-744.

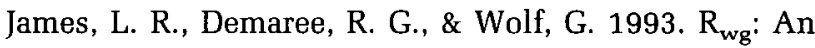
assessment of within-group interrater agreement. Journal of Applied Psychology, 78: 306-309.

Jöreskog, K. G. \& Sörbom, D. 1993. LISREL 8: Structural equation modeling with the SIMPLIS command language. Chicago: Scientific Software International.

Liang, D. W., Moreland, R., \& Argote, L. 1995. Group versus individual training and group performance: The mediating role of transactive memory. Personality and Social Psychology Bulletin, 21: 384-393.

Locke, E. A., \& Schweiger, D. M. 1979. Participation in decision-making: One more look. In B. M. Staw (Ed.), New directions in organizational behavior, vol. 1: 265-339, Greenwich, CT: JAI Press.

Mathieu, J. E., Heffner, T. S., Goodwin, G. F., Salas, E., \& Cannon-Bowers, J. A. 2000. The influence of shared mental models on team process and performance. Journal of Applied Psychology, 85: 273-283.

Miller, K. I., \& Monge, P. R. 1986. Participation, satisfaction, and productivity: A meta-analytic review. Academy of Management Journal, 29: 727-753.

Mischel, L. J., \& Northcraft, G. B. 1997. "I think we can, I think we can ..." The role of efficacy beliefs in group and team effectiveness. In B. Markovsky et al. (Eds.), Advances in group processes: 177-197. Greenwich, CT: JAI Press.

Mitchell, T. R. 1973. Motivation and participation: An integration. Academy of Management Journal, 16: $670-679$.

Riggs, M. L., Warka, J., Babasa, B., Betancourt, R., \& Hooker, S. 1994. Development and validation of selfefficacy and outcome expectancy scales for jobrelated applications. Educational and Psychological Measurement, 54: 793-802.

Schaubroeck, J., Lam, S. S. K., \& Xie, J. L. 2000. Collective versus individual self-efficacy in coping responses to stressors and control: A cross-cultural study. Journal of Applied Psychology, 85: 512-525.

Schuler, R. S. 1980. A role and expectancy model of participation in decision making. Academy of Management Journal, 23: 331-340.

Siegel, A. L., \& Ruh, R. A. 1973. Job involvement, partic- ipation in decision making, personal background, and job behavior. Organizational Behavior and $\mathbf{H u}$ man Performance, 9: 318-327.

Triandis, H. C. 1989. Self and social behavior in differing social contexts. Psychological Review, 96: 269-289.

Triandis, H. C. 1994. Culture and social behavior. New York: McGraw-Hill.

Triandis, H. C., \& Gelfand, M. J. 1998. Converging measurement of horizontal and vertical individualism and collectivism. Journal of Personality and Social Psychology, 74: 118-128.

Wagner, J. A. 1994. Participation's effects on performance and satisfaction: A reconsideration of research evidence. Academy of Management Review, 19: 312-330.

Wagner, J. A., \& Gooding, R. Z. 1987a. Effects of societal trends on participation research. Administrative Science Quarterly, 32: 241-262.

Wagner, J. A., \& Gooding, R. Z. 1987b. Shared influence and organizational behavior: A meta-analysis of situational variables expected to moderate participation-outcome relationships. Academy of Management Journal, 30: 524-541.

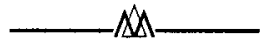

Simon S. K. Lam (simonlam@business.hku.hk) received his Ph.D. from Australian National University. $\mathrm{He}$ is an associate professor of management at the School of Business, University of Hong Kong. His research focuses on quality management, work-related commitments, and cross-cultural human resource management.

Xiao-Ping Chen received her Ph.D. from the University of Illinois at Urbana-Champaign. She is an associate professor in the Department of Management and Organization at the University of Washington. Her current research interests include group dynamics, decision making, conflict management, leadership, organizational citizenship behavior, employee turnover, and cross-cultural management.

John Schaubroeck is currently a professor of management and the head of the Department of Management, LeBow College of Business, Drexel University. He received a Ph.D. in organizational behavior and human resource management from Purdue University. His research interests include work stress and coping and cross-cultural issues in organizational behavior. 
Copyright of Academy of Management Journal is the property of Academy of Management. The copyright in an individual article may be maintained by the author in certain cases. Content may not be copied or emailed to multiple sites or posted to a listserv without the copyright holder's express written permission. However, users may print, download, or email articles for individual use. 